I Kannel, W. B., Castelli, W. P., Gordon, T., and McNamara, P. M., Annals of Internal MediMartins, $F$. M European Congress of Cardiology. 1972

3 Watson, D., Clinica Chimica Acta, 1960, 5, 637. Wochensch, 1966, 44, 262

Canal, J., and Ricquois, M., Feuillets de Biologie, 1971, 12, 53.

Steiner, P., and Pearce, W., Metabolism, 1971,
Schoenfeld, M.,

Miguel, M. J. P., et al., Annales de Biologie

\section{Psychiatric Nurse as Therapist}

SIR,-Dr. I. M. Marks and his colleagues are to be congratulated on their welldesigned paper (21 July, p. 156) which raises a number of topical issues, especially for those engaged on similar ventures.

At this unit we have, since 1961 , operated an 18-month postgraduate course for nurses who hold as their basic gualification at least the S.R.N. or R.M.N. The regional hospital board allocates four bursaries (equivalent to a staff nurse's salary) and, in conjunction with the Portsmouth Polytechnic, a special diploma is awarded to candidates after successful completion of the training. Despite obvious differences in clinical approach and setting, our aims are not unlike those outlined by Dr. Marks-for example, the use of behaviour modification through the repeated coupling of two individuals" or small "transactional" groups for mothers and pre-school children, involving social comparison processes, especially modelling. ${ }^{2}$ Our curriculum seeks to impart a substantial body of theoretical knowledge, authenticated by continuous practical involvement and the sharing of learning experience with other team members by means of study groups, tutorials, and seminars. There is increasing emphasis on extramural work, follow-ups, and crisis intervention.

Because much of our enterprise deals with multidimensional family systems rather than individuals, it is harder to apply "accurate measurements" to a comparison of therapeutic effectiveness. Frequently a nurse therapist replaces absent or "invalid" parents; or he or she might have to feed back specific activity cues into the home of an autistic child. Nonetheless, we would agree with all the general comments made about the value and functional aspects in the training of nurse theramists. A recent cost analysis points to a possible reduction in drug expenditure; and a prospective study of "breakdown recurrence," now under way, suggests no significant difference between patients treated by nurses and other therapists. The problem of grading on the Salmon scale seems to us of paramount importance. If so much effort is being devoted to training and skilled nurse therapists become ultimately sidetracked into administration, one might perhaps auestion if this constitutes "the most rational deployment of N.H.S. personnel."-I am, etc.,

Christopher HAFFner

Wessex Unit for Children and Parents,

Portsmouth, Hants I Haffner, C., Deutsche Schwesternzeitung, 1968 ,
10, 601.
2 Mundy, L., Fournal of Child Psychotherapy, 1972,
3,77. 3, 77 .

SIR,-I found the paper by Dr. I. M. Marks and others (21 July, p. 156) very interesting.
I am aware of a somewhat similar attempt in Canada which was not too successful. However, in this instance attempts were made to utilize the Canadian equivalent of state enrolled assistant nurses, probably because they were the only staff readily available at the time. I note, too, that Dr. Marks and his colleagues were able to select their five trainees out of 80 applicants.

Secondly, the authors say that "qualified therapists need to be linked either to psychiatrist or to a psychologist." I wonder how they would perform if they found themselves in a post where the psychiatrist or psychologist was either not as enthusiastic as the authors for utilizing nurses in this way or, possibly more important, was not as well informed in behaviour therapy principles and practice as the authors (or possibly even the nurse-therapist)? I am now a little out of touch with the situation in Britain, but centainly in Canada there are still many areas where knowledge of these is somewhat limited. I am not entirely clear whether the authors feel these nurse-therapists could function adequately in such a situation. In other words, could they function where the psychiatrist acted purely as a referrer of patients, or do they require that either he or the psychologist act in a supervisory capacity?

In view of recent evidence suggestive of the advantages in some conditions of in vivo (or in practice) exposure over the use of fantasy (or imagination), the use of some such therapists becomes even more important, particularly on account of the time factor involved. I think, therefore, that it would be a pity if what potentially seems to be a very useful development were to fall into disrepute through misusage.-I am, etc.

Michael J. C. Thomson

Department of Preventive Medicine

Dalhousie University
Halifax, Nova Scotia

\section{Drug-induced Antiplatelet} Antibodies

SIR,-Thrombocytopenia is a well-recognized complication of treatment with phenylbutazone and generally results from marrow hypoplasia. However, in a recent case in this hospital a specific platelet antibody was also present, and as far as we are aware this has not previously been recorded.

The patient, a 58-year-old Caucasian woman, was admitted with one week's history of bruising. Six weeks before admission she had been prescribed phenylbutazone $100 \mathrm{mg}$ thrice daily for low back pain, which she had continued up to the time of admission. Otherwise she had had no recent medication of any kind, and her job as a finisher in tailoring had not exposed her to any unusual chemicals.

On admission she was found to have widespread bruising on the limbs, but there was no evidence of bleeding elsewhere and the spleen was not palpable. The initial blood count showed: haemoglobin $10.9 \mathrm{~g} / 100 \mathrm{ml}$, W.B.C. $2,800 / \mathrm{mm}^{3}$ (neutrophils $330 / \mathrm{mm}^{3}$ ), platelets $4,600 / \mathrm{mm}^{3}$, E.S.R. $39 \mathrm{~mm}$ in one hr. The blood film was normocytic and normochromic and the reticulocyte count was $1.4 \%$. Routine investigations showed normal blood urea and electrolyte levels, liver function tests, and chest $x$-ray and negative rheumatoid factor, latex and antinuclear factor tests. Serum proteins were $6.2 \mathrm{~g} / 100 \mathrm{ml}$ (albumin $3.7 \mathrm{~g} / 100 \mathrm{ml}$, globulin $2.5 \mathrm{~g} / 100 \mathrm{ml}$ ); protein electrophoresis demonstrated an increase in the $a$-globulin and quantitative immunoglobulin estimations an increase in IgM (IgG $510 \mathrm{mg} / 100 \mathrm{ml}$, IgA $165 \mathrm{mg} / 100 \mathrm{ml}$, IgM $430 \mathrm{mg} / 100 \mathrm{ml}$ ). Plasma haptoglobin level was $200 \mathrm{mg} / 100 \mathrm{ml}$ and the direct Coombs test negative. The sternal marrow aspirate showed some reduction in cellularity; erythopoietic and granulopoietic activity was normal, but there was a relative decrease in the number of mature granulocytes. Lymphocytes and plasma cells appeared normal, but the number of megakaryocytes was reduced.

Investigations for platelet and leucocyte anti-

bodies were carried out. For platelets the saline agglutination test at $4^{\circ}, 20^{\circ}$, and $37^{\circ} \mathrm{C}$ was negative, complement fixation test at $37^{\circ} \mathrm{C}$ was positive in the presence of phenylbutazone in a concentration of $1 \mathrm{mg} / \mathrm{ml}$, and the Coombs consumption test at $20^{\circ} \mathrm{C}$ gave a negative result. For leucocytes the saline agglutination test at $4^{\circ} \mathrm{C}, 20^{\circ}$, and $37^{\circ}$ was negative and the complement fixation test at $37^{\circ} \mathrm{C}$ was negative.

The patient was treated with prednisolone, $60 \mathrm{mg} /$ day for 3 weeks when most of the bruising had subsided and she was discharged taking $30 \mathrm{mg} / \mathrm{day}$, the dosage being slowly tailed off over the next four months. There was a gradual improvement in all parameters of the blood count, and at four months the haemoglobin, W.B.C., and platelet count had returned to the normal range. The patient has been entirely symptom-free since her discharge from hospital.

Though drug-induced thrombocytopenia has been described following a large variety of drugs, in only a few has a specific platelet antibody been described. 1 In this patient the general pancytopenia and the hypocellular marrow suggest that the major effect of phenylbutazone was direct marrow toxicity, and this is supported by the slow haematological response despite the use of steroids. However, both direct marrow suppression and platelet destruction by specific antibodies are recognized in the thrombocytopenia seen with thiazides. ${ }^{2} 3 \mathrm{We}$ are postulating a similar mechanism for the thrombocytopenia caused by phenylbutazone in our patient, and suggest that antiplatelet antibodies should be sought for in all cases of this type.

We would like to thank Dr. Maxwell Telling for permission to report this case.

-We are, etc.,

C. Davidson General Infirmary,
Leeds

S. M. ManohitharajaH

1 Aster, R. H., in Haematology, ed. W. J., Williams, E., Bentler, A. J., Erslev, and $\mathbf{R}$. W., Rundles, New York, McGraw-Hill, 1972.
Rodrigues, S. U., Leikin, S. L., and Hiller, M C., New England fournal of Medicine, 1964, 270, 881. V., and Crowell, E. B., fournal of the American Medical Association, 1971, 215,

\section{Infectious Mononucleosis}

SIR,-I have read with interest the article by Dr. H. Pullen (12 May, p. 350). Infectious mononucleosis still represents a rather frequent haemopathy with peculiar features and some obscure nosological aspects. In $\mathrm{Dr}$. Pullen's article the description of the clinical symptomatology fails to include two signs which may be very useful in practice.

The first is eyelid oedema, which may cause narrowing of the palpebral fissure. According to Hoagland and Wintrobel this symptom occurs in $36 \%$ of cases. But its diagnostic importance increases because of its early appearance, as confirmed by my recent observations.

The second feature missing from the article is the pain caused by the swollen lymph nodes. In certain cases of lymphaden-

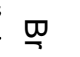 든 $\ddot{\bar{C}}$ . $\overrightarrow{0}$ .

